\title{
Validation of an integrated simulation model for aircraft noise and engine emissions
}

DOI:

10.1016/j.ast.2019.04.008

\section{Document Version}

Accepted author manuscript

Link to publication record in Manchester Research Explorer

\section{Citation for published version (APA):}

Filippone, A., Zhang, M., \& Bojdo, N. (2019). Validation of an integrated simulation model for aircraft noise and engine emissions. Aerospace Science and Technology. https://doi.org/10.1016/j.ast.2019.04.008

\section{Published in:}

Aerospace Science and Technology

\section{Citing this paper}

Please note that where the full-text provided on Manchester Research Explorer is the Author Accepted Manuscript or Proof version this may differ from the final Published version. If citing, it is advised that you check and use the publisher's definitive version.

\section{General rights}

Copyright and moral rights for the publications made accessible in the Research Explorer are retained by the authors and/or other copyright owners and it is a condition of accessing publications that users recognise and abide by the legal requirements associated with these rights.

\section{Takedown policy}

If you believe that this document breaches copyright please refer to the University of Manchester's Takedown Procedures [http://man.ac.uk/04Y6Bo] or contact uml.scholarlycommunications@manchester.ac.uk providing relevant details, so we can investigate your claim.

\section{OPEN ACCESS}




\title{
Validation of an integrated simulation model for aircraft noise and engine emissions
}

\author{
Antonio Filippone*, Mengying Zhang, Nicholas Bojdo \\ The University of Manchester \\ Manchester M13 9PL
}

\begin{abstract}
A summary is given of the validation of an integrated aircraft environmental simulation software, with focus on acoustic and engine exhaust emissions. First, an experimental campaign was carried out to gather noise data of several commercial aircraft on departure from Manchester airport (ICAO code: EGCC). Field measurements were taken with microphones placed at a point $8,500 \mathrm{~m}$ (4.6 n-miles) from the estimated brake-release point. The departure measuring point was chosen due to the variability in flight trajectories. Comparisons between measurements and numerical predictions are shown for 12 commercial airplanes: A319-111, A320-214, A321211, A330-243, A330-343, A350-900, A380-861, B737-800, B757-200, B787-800 and -900 versions, and finally the ERJ-195. The validated airplane models are used with a multi-objective, multiparameter trajectory optimisation at the same airport to determine optimal departure profiles for airplanes in three weight classes: commuter jet, medium range transport, and long-range transport. It is demonstrated how different or concurrent cost functions (noise, fuel consumption, environmental price) lead to considerably different flight profiles and environmental emissions.
\end{abstract}

\section{Nomenclature}

$\begin{array}{llll}C & =\text { cost function } & V_{g} & =\text { ground speed } \\ F_{N} & =\text { net thrust } & V_{w} & =\text { wind speed } \\ J_{1}, J_{2} & =\text { optimiser cost functions } & \boldsymbol{V} & =\text { vector } \\ L_{A} & =\text { (or LA) A-weighted noise level } & V(x) & =\text { total preference value } \\ L_{A E} & =\text { sound exposure level } & \mathcal{V} & =\text { sensitivity vector } \\ m & =\text { mass } & W_{f 6} & =\text { fuel flow } \\ M & =\text { total number of objectives } & \boldsymbol{x}(x, y, z) & =\text { aircraft position } \\ n_{i} & =\text { preference values } & \alpha & =\text { airplane attitude } \\ N_{1} & =\text { engine speed } & \gamma & =\text { climb angle } \\ P_{a i r} & =\text { atmospheric pressure } & \theta & =\text { airplane heading } \\ P & =\text { awakening probability } & \phi & =\text { airplane bank angle } \\ \mathcal{P} & =\text { population size/density } & \psi & =\text { airplane heading } \\ r_{i} & =\text { uncertainty value } & \Psi_{w} & =\text { wind direction } \\ \mathrm{SEL} & =\text { Sound Exposure Level } & {[\cdot]} & =\text { mean value } \\ t & =\text { time } & (.)_{c} & =\text { control point } \\ T_{a i r} & =\text { atmospheric temperature } & (.)_{o} & =\text { initial conditions } \\ U & =\text { unit cost } & (.)_{f} & =\text { final conditions } \\ \mathrm{UDC} & =\text { unit damage cost index } & & \end{array}$

${ }^{*}$ Corresponding address: School of MACE, George Begg Building, E-mail: a.filippone@manchester.ac.uk 


\section{Introduction}

The simulation of aircraft environmental emissions, and specifically noise, lags behind other engineering simulations, although considerable progress is being demonstrated in the technical literature. Aside from detailed computational aero-acoustics at the level of isolated components (for example, jets or high-lift surfaces), the task of predicting aircraft noise and emissions relies on a vast number of data, assumptions and models. Often the database required is incomplete, imperfect or unreliable. This situation requires assumptions, not all directly verifiable, in support of reduced-order models. The current needs are split into three categories:

1. Models that rely on "best-practice" and use databases in order to make quantitative assessments of airfield noise. These models provide rapid answers to extremely complex scenarios involving multiple aircraft movements on a typical day. Computer codes on this line of thought include $\mathrm{INM}^{1}$ and its later evolutions (including the FAA Aviation Environmental Design Tool, AEDT), ANCON2 in the UK ${ }^{2}$, the European ECAC Doc. $29^{3}$, the ICAO general method ${ }^{4}$ and a plethora of national initiatives leading to noise simulation models that apply to a set of airfields.

2. Models that rely on physical and engineering models, sometimes closed with empirical databases to provide detailed acoustic predictions for aircraft in the conventional configuration (tube-andwing), either at the preliminary design stage or as existing airplanes. We call models in this category "scientific methods". One of these methods is developed by the authors and briefly discussed in this paper.

3. Models as in the previous category, with capabilities in areas such as noise interference, advanced propulsion systems, and emissions analysis, that are used to provide acoustic predictions for unconventional aircraft, new conceptual designs, and trade-off analysis. The prime example in this category is ANOPP2 ${ }^{5}$, but there are other examples, such as Ref. ${ }^{6}$ to deal with blended wing-bodies and Ref. ${ }^{7}$ for various configurations that include noise shielding.

A full review of the state-of-the-art is available in Ref. ${ }^{8}$, and will thus not be repeated here. Best-practice methods offer answers with some limited explanations. By contrast, scientific methods attempt to offer explanations and answers. For example, they help explore the contribution of various sub-systems to overall noise emission. Thus, they can guide the research toward the most effective strategies for noise reduction at the source, or toward the best operational strategies that minimise impact on specific areas around the airfield, including trajectory optimisation. In the latter case, noise prediction methods are used to infer noise differences between trajectories, rather than as absolute values. In the long term, we aim for a reliability that is sufficient for noise certification.

There are only a few examples of complete field data taken for the purpose of noise validation. For 
example, Guerin et al. ${ }^{9 ; 10}$ report noise measurements taken in combination with flight data, which allows for the correct airplane position and engine settings to be defined in a noise simulation problem. There are examples in the technical literature that address more sophisticated and detailed measurements, using beam-forming techniques to identify noise sources and their respective locations ${ }^{11}$. These data are useful to identify directivity functions and prioritise noise abatement techniques. However, noise levels vary considerably among different flyovers, even for the same airplane ${ }^{12}$; this causes difficulties when assessing the true contribution of a noise source.

In recent years, some advances have been demonstrated in the technical literature (for example, noise source identification and breakdown; detailed analysis of multiple noise metrics), but the scientific approach still has limited traction in comparison with best-practice methods that rely on extensive databases that are able to produce surrogate trajectories, noise-power-distance relationships and complete noise footprints around airfields. These models facilitate very general assessments and are instrumental in the definition of noise zones around important airfields - something which can be of national importance, well beyond the technical aspect.

At the opposite end of the simulation spectrum, high-fidelity computer codes are currently prohibitive in terms of times and computing costs, and are thus limited for more detailed sub-component analysis at a limited number of operation points. This status is unlikely to change for the foreseeable future. This leaves us with low-order noise simulation procedures such as the ones described in this paper. These methods are developing rapidly, with increasing amounts of physics at a limited computational burden. Nevertheless, there is only scant code-to-code comparison, or comparisons with flyover data to validate these methods with real-world events. Comparisons with measured flyover trajectories are currently the best way to advance our simulation capabilities in this field of aircraft engineering.

Exhaust emissions are associated to the engine state and depend on complex combustion chemistry. Such complexity is circumvented by using emission indices at key operating points for the main pollutants $\left(\mathrm{NO}_{x}, \mathrm{CO}, \mathrm{UHC}\right)$. Relationships between fuel flow, engine rotational speed and emissions have been established for modern engines that allow a reasonable prediction of emissions ${ }^{13}$ from turbofan engines. Similar relationships are used in work shown here to complete the aircraft noise model with emissions, to yield a comprehensive emission analysis software. Fuel flow comparisons between FDR and our computer codes were previously published in Refs. ${ }^{14 ; 15}$.

Specifically, this paper addresses three contributions. One is the development of an airplane database and the other is the field data sets used for this validation. The current software version (FLIGHT) contains about 50 different aircraft with engine combinations, including turboprops, turbofans and cargo/freighter versions; noise validation for departure flights of 12 of these aircraft is demonstrated in this paper. Another contribution is the addition of a sophisticated multi-objective trajectory optimisation mathematical model, which allows integrated environmental emissions, sub- 
ject to a variety of cost limiters. Finally, the environmental model is applied to a real case of an airport to demonstrate how emissions minimisations are applied on a real map. A departure trajectory has been chosen in order to attempt to minimise aircraft emissions above a major town south of the airfield.

\section{Aircraft Noise Measurements}

The airfield was Manchester airport, which is a major commercial airport with over 200,000 movements per year and about 28 million passengers. There is currently a limit of 60 flights/hour by using two parallel runways, one of which is unused during night time.

Microphone Position. A field measurement setup was established at GPS location (53.318660, $-2.366325)$, which is in an open field with grassland, near a lake, away from road traffic. This point was chosen because it is sufficiently close to the airfield and to the town of Knutsford (reference GPS: $53.3048,-2.3766$ ); the town is just South of westbound departures ( $\sim 80 \%$ of occurrences) and below the flight track for eastbound landings ( $\sim 20 \%$ of occurrences).

The exact brake-release point was not known, but it was established empirically at 8,500 m (4.6 n-miles) from the microphone from examination of digital maps of the airfield. This point is 5.69 $\mathrm{km}$ from the South edge of runway $23 \mathrm{R}$ and $3.97 \mathrm{~km}$ from runway 23L. In a past exercise, we noted that radar tracks are too inaccurate for the determination of the aircraft position, and even the GPS location from the on-board flight data recorder could be inaccurate by more than one wing span ${ }^{14}$.

Outbound flights at this airfield tend to follow a North-West trajectory to avoid the built-up community of the town of Knutsford; this is known as SANBA 1R or 1Y noise preferential routing, Figure 1. Therefore, it is very likely that ground tracks are slightly curved toward the noise measurement point, leading to a total flight path slightly in excess of $8.5 \mathrm{~km}$. Due to the large source-receiver distance (several hundred metres), lateral ground track dispersion is unlikely to have any important effects on the numerical results.

Atmospheric Conditions. Atmospheric conditions reported by METAR were as follows: temperatures between 4-8 degrees Celsius on day-one and 7-11 degrees Celsius on day-two; wind speeds 2-3 kt on day-one and 3-7 kt on day-two, from the W-S-W, with 0-40 degree variability. The cloud base was between 600-1,700 feet AGL on day-one and 100-1,700 feet on day-two. In all cases there was mist or drizzling rain. In summary, this was a winter period with minor precipitation, negligible winds, very low cloud base, poor visibility and high humidity level. These conditions are clearly different from a standard day. 


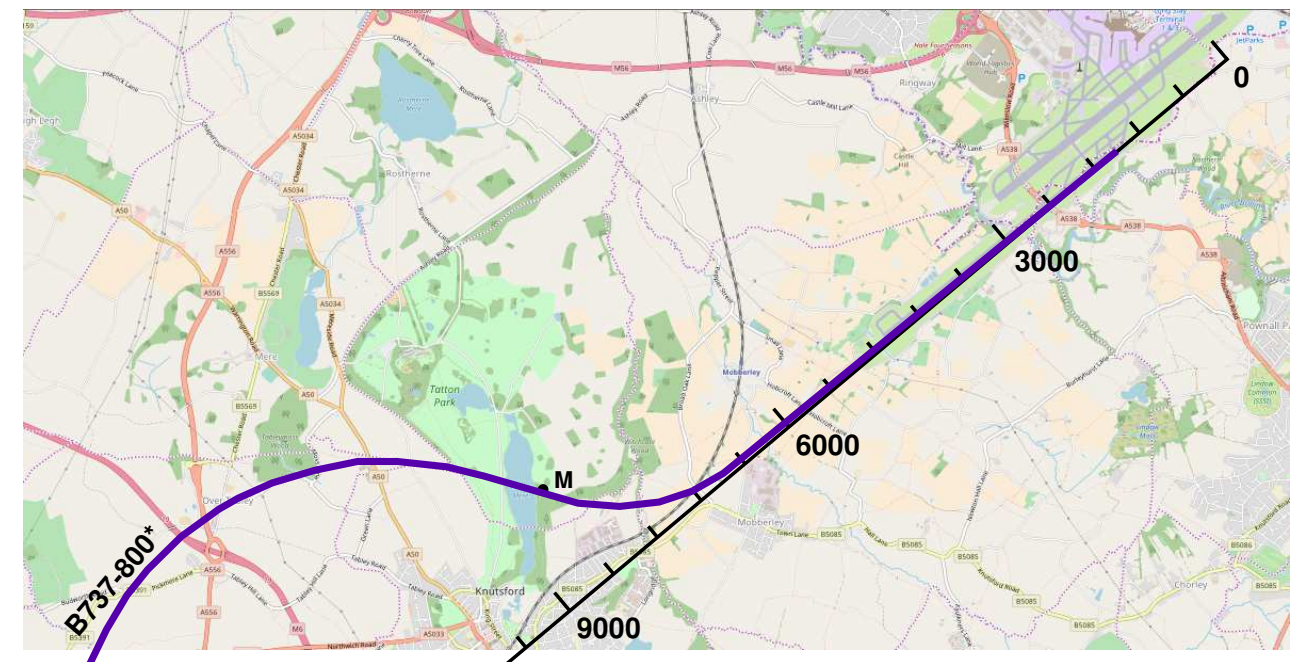

Figure 1: SANBA $1 Y$ (runway 2) noise routing of a Boeing B737-800 departing from Manchester airport; data elaborated from the PlaneFinder App, mapped with OpenStreetMaps; $M$ denotes the microphone position.

Measurement Set-up. Fly-over noise was measured using a Brüel \& Kjaer (B\&K) Type 2250 Sound Level Meter (SLM). This is a Class-1 SLM conforming to International Electrochemical Commission 61672-1:2013 international standard. The microphone was mounted on a tripod at a height of $1.2 \mathrm{~m}$ above ground level in compliance with the noise measurement practice. The microphone was placed horizontally, with the diaphragm parallel to the flight path to minimize directivity effects. The SLM was calibrated using a Class-1-compliant B\&K Type 4231 sound calibrator prior to taking noise measurements; calibration was done every hour.

The SLM was set to run in logging mode to measure the broadband and $1 / 3$-octave band levels with 1-second time increment (the shortest value available for type $2250 \mathrm{SLM}$ ). At the same time, the integral metrics were computed using the slow time setting ( 1 second integration time). These data, along with A-weighted and unweighted sound pressure level values, were stored towards the end of each logging period. SPL values were also logged using a logging period of $100 \mathrm{~ms}$ to provide a higher resolution of the measurement content.

The fly-over noise measurements were initiated manually on sight of the approaching aircraft and terminated manually when the noise level had dropped to near-background levels or such that the measurement had been taken for a sufficiently long duration. This manual operation gave the operator more control over the duration of each measurement, alongside ensuring extraneous nonaircraft noise was not measured. The operator left the SLM for the duration of the noise event; additional noise induced by the motion of the operator could be recorded. For this reason, the first and few last seconds of each measurement were ignored to improve accuracy. 
Background Noise. The background noise readings were periodically recorded for at least one minute when there were no approaching or receding aircraft and no additional audible noise sources. The content of the recording was annotated for each background noise measurement. The SLM was used in the same configuration as for taking aircraft fly-over noise measurements with the broadband and 1/3-octave band levels logged. The number of background readings taken depended on the following three factors:

1. The amount of time spent to take aircraft noise measurements at the location

2. The presence of new noise sources that increased the background noise level significantly

3. The number of occasions when there was long enough between aircraft movements to take background measurements.

The A-weighted background noise levels, averaged over all individual background noise readings, for the two days were approximately $46.71 \mathrm{dBA}$ and $44.02 \mathrm{dBA}$ respectively, providing an approximate noise floor for the measured aircraft noise.

Airplane Identification. Aircraft flying past the measurement point were to be identified from their registration number, for most cases, observed underneath the port wing by using a pair of binoculars. However, due to cloudy weather, the registration number could not always be identified. For this reason, a web application was used as an alternative to locate approaching aircraft and the given aircraft registrations and aircraft types were noted. During post-processing, passing aircraft were validated using the "Flight Radar" application and the "WebTrak" service, which is used to monitor air transport movements and noise data by Manchester Airport. The details of the aircraft were thereupon checked against the data retrieved from the Aircraft Registration Database.

\section{$3 \quad$ Aircraft Noise Simulations}

The computer code used for the present work has been already documented in several previous publications, including but not limited to Ref. ${ }^{16 ; 17 ; 14}$. Previous comparisons with fly-over data include those reported in Ref. ${ }^{18}$, and included both landing and take-off for a limited number of aircraft types. A recent application of the computer code ${ }^{19}$ addressed optimisation of A320-200 departure trajectories from Manchester airport, and it was demonstrated how it is possible to determine accurate differential noise footprints.

In this instance, it is recalled that the computer code is fully multi-disciplinary, and models the entire aircraft (geometry, mass distributions, configuration aerodynamics, propeller aerodynamics, flight mechanics, numerical optimisation, gas turbine propulsion and other aspects of modern fixedwing aircraft). The computer code relies on a large number of inputs that have to be provided in 
order to define the airplane, the engine, the external conditions and the flight conditions. Sensitivity analysis is used to verify all the assumptions.

The simulation procedure is the following: a trajectory is established on the basis of a tentative mission profile, which requires guessing the mission range, the required payload and other flightspecific parameters; these include, but are not limited to, engine derating and climb-out procedure (typically: NADP, ICAO-A, ICAO-B, or others). The trajectory is determined when there is convergence between the estimated brake-release gross weight and the brake-release gross weight arising from the sum of all loaded mass contributions. Since specific data on the measured trajectories were unavailable, it was assumed that the flight path was slightly curved and passing above the measurement point. It was also assumed that our ground microphone position was within one wing span from the ground track.

The most important aspect of the numerical methods used in the computer code is that the long calculation chain, from the airplane's geometrical configuration to noise measured at the receiver, requires a balanced approach, wherein the critical step is the weak link. This link is not always identifiable. For example, for a turbofan-powered airplane, the noise is dominated by the fan on approach to the receiver and by the jet on departure from the receiver. At the overhead position the two sources are comparable, but the exact contribution depends on the aircraft and the flight procedure. For these reasons, focus should be on these two noise sources.

The computer code has a large set of airplane models and their respective engines, to cover about $80 \%$ of the commercial worldwide traffic. Additionally, there is a database of models for military transport aircraft and detailed airport models. A typical airplane model consists of the following:

- Geometry configuration file, defined by a set of cards and control points, which allows a full determination of positions, lengths, areas, centroids and mass distribution. This configuration is passed to the aerodynamics module, which requires also aerodynamic derivatives. Furthermore, there is a furnishings configuration file for the determination of the internal arrangement of the cabin and the position of the centre of gravity.

- Aerodynamic derivatives file, defined by a set of common derivatives for all the lifting surfaces the main flight controls (ailerons, flaps, elevators, rudders).

- Propeller model, defined by a geometric configuration, blade sections data, and aerodynamic polars (look-up tables) at one reference Mach number.

- Engine model, defined by a set of flight envelopes covering a full range of air temperatures, flight Mach numbers, flight altitudes and engine speeds. About 25 aero-thermodynamic parameters are normally used for flight, emissions and noise calculations. 
- Airplane model data, consisting of about 50 critical parameters, from certified weights to tyre dimensions.

- Engine model data, consisting of about 50 critical engine parameters, including general dimensions, nozzle, fan, intake configuration, and reference emission indices.

- APU model data, consisting of a flight envelope and basic performance data, such as fuel flow, output power and in some case emission data.

In addition to the above, up to 100 fixed parameters are used at various levels to complete the airplane model (engine geometric data, operational data, flight limitations, etc.)

The airplane model is checked at several levels, including the sub-system analysis (geometry, aerodynamics, weights, centre of gravity, engine performance, point performance), until a full confidence is reached, when no major discrepancy with known parameters is found, after passing through several hundred check-points.

The noise calculation is split from the flight analysis. When the trajectory is completed, a vector of time-dependent variables ${ }^{16}$ is generated (interface file):

$$
\boldsymbol{V}(t)=\left(\boldsymbol{x}, \theta, \phi, \psi, \mathrm{IAS}, \mathrm{TAS}, V_{g}, F_{N}, N_{1}, W_{f 6}, \mathrm{LGear}, \mathrm{iSF}, T_{a i r}, P_{a i r}, R H, V_{w}, \Psi_{w}\right)
$$

where $\boldsymbol{x}$ is the position vector, $\theta, \phi, \psi$ are the attitude, bank angle and attitude angle respectively; IAS, TAS, $V_{g}$ are the indicated air speed, true air speed, and ground speed, respectively; $F_{N}, N_{1}$ and $W_{f 6}$ are the required net thrust, engine speed and fuel flow, respectively; LGear, iSF are the landing gear position and slat-flap settings, respectively; $T_{a i r}, P_{a i r}, \mathrm{RH}, V_{w}, \Psi_{w}$ are atmospheric parameters at the airplane position $\boldsymbol{x}$ : air temperature, pressure, relative humidity, in addition to wind speed and wind direction. This interface file allows the exchange of critical data with other computer programs. The gross weight $W$ at the start of the trajectory must be given if the trajectory is self-generated by the computer code. The weight would not be required if data from the FDR are available; in this case, the most important parameters would be the engine speed $\mathrm{N} 1 \%$ and the fuel flow $W_{f 6}$. Note that the availability of both fuel flow and engine rotational speed throughout the entire flight can be used alongside emission indices to provide an accurate estimate of the exhaust emissions ${ }^{15}$. We will focus essentially on the $\mathrm{CO}_{2}$ emissions, which are proportional to fuel burn and hence can be derived directly from Eq. 1 without further modelling being required.

Most of the data required by the vector Eq. 1 are stored in the FDR. The time sampling is $\sim 1 \mathrm{~s}$, but variable from take-off to a reference altitude of 3,000 feet above ground level. All calculations are performed as quasi-steady state, since the time step is too large to be considering transient effects on the engines. 


\section{Acoustic Results and Discussion}

Results are shown for departure trajectories for a selected number of aircraft. In the analysis that follows, comparisons with noise simulations are shown alongside the measurements. The time frame is always taken as 60 seconds ( \pm 30 seconds around the overhead position). The noise level is always contained within the range 40-90 dBA. Most of the graphs show the slow-mode A-weighted sound pressure level $\left(L_{A}\right.$, sometimes called $\left.L_{A s}\right)$, and in a few cases the equivalent sound-level $L_{A e q}$. The $L_{A}$ is shown either as a continuous line (when a statistical analysis of the data is used), or as a set of symbols (when only a few trajectories are available). In the latter case, data points are plotted every $0.5 \mathrm{~s}$ for clarity. The measured data are available at $0.1 \mathrm{~s}$ intervals. The trajectories and the corresponding labels contain the identifier [x-nnn], where $\mathrm{x}=1,2$ is the measurement day; " $\mathrm{nnn}$ " is the measurement number. On all the graphs shown the airplane is to be interpreted as moving from the left (upstream) to the right (downstream).

Atmospheric and External Conditions. The METAR data show some variability in temperature and relative humidity. The numerical simulations were all carried out at a temperature of 7 degrees, with a wind speed $2 \mathrm{kt}$ on the ground, and a stable relative humidity of $95 \%$. Wind speeds less than $3 \mathrm{kt}$ make no difference in the noise propagation; the relative humidity is more critical and would need to be entered as a space variable. The propagation model used is a modification of the wave-equation approach of Rasmussen and Almgren ${ }^{20 ; 21}$. This method balances computational effort with accuracy by being able to conduct a propagation analysis in a practical amount of time; this is about 30-40 s on a desktop computer for a departure trajectory.

The background noise is included in the numerical simulations. Background noise does not affect peak noise level, but it is comparable to the airplane's noise level at flight times $\pm 25 \mathrm{~s}$ from the overhead position, as demonstrated below.

Summary of Measured Data. A summary of measured noise is given in Table 1, which contains data for 12 different airplane types and versions. The last column to the right is the predicted $L_{A}$ value, $L_{A}^{*}$. It is to be noted that the variation in peak $L_{A}, \Delta L_{A m a x}$, is in excess of $5 \mathrm{dBA}$ for three airplanes, whilst for others there can be too few trajectories to make a statistical assessment; such is the case of the Embraer ERJ-195. This is no different than other measurements available in the technical literature ${ }^{12}$. One trajectory of the B757-200 showed much lower noise level than the other data and it was excluded from the analysis, although it will be later shown in the noise comparisons.

Comparisons between Measurements and Simulations. To begin with, Figure 2 and Figure 3 show the comparisons for the Airbus A319-111 and A320-214, respectively. For this airplane, 5 departure trajectories were available. For the A320 we had 11 trajectories; the trajectories with 
Table 1: Measured noise metrics: $\dagger=$ excluding one flyover; $\ddagger=$ single value; ${ }^{*}=$ predicted

\begin{tabular}{rlccccc}
\hline & Airplane & $L_{A \max }$ & $\bar{L}_{\text {Amax }}$ & $\Delta L_{\max }$ & $\bar{L}_{A E}$ & $L_{\text {Amax }}^{*}$ \\
\hline 1 & $\mathrm{~A} 319-111$ & 78.6 & 75.0 & 5.3 & 84.1 & 73.8 \\
2 & $\mathrm{~A} 320-214$ & 76.9 & 74.4 & 5.6 & 83.5 & 74.8 \\
3 & $\mathrm{~A} 321-211$ & 78.0 & 77.7 & 0.7 & 86.8 & 76.3 \\
4 & $\mathrm{~A} 330-243$ & 77.9 & 76.2 & 3.0 & 87.1 & 79.6 \\
5 & $\mathrm{~A} 330-343$ & 81.1 & 80.6 & 0.9 & 91.2 & 79.3 \\
6 & $\mathrm{~A} 350-941$ & 73.6 & 75.0 & 3.5 & 85.2 & 78.5 \\
7 & $\mathrm{~A} 380-861$ & 80.1 & 77.9 & 4.5 & 87.9 & 81.1 \\
8 & $\mathrm{~B} 737-800$ & 78.9 & 75.8 & 5.6 & 84.8 & 77.3 \\
9 & $\mathrm{~B} 757-200^{\dagger}$ & 78.9 & 77.1 & 3.6 & 85.9 & 75.4 \\
10 & $\mathrm{~B} 787-800$ & 80.0 & 78.1 & 4.1 & 85.9 & 79.3 \\
11 & B787-900 & 75.7 & 74.5 & 2.4 & 85.1 & 76.0 \\
12 & ERJ-195 & 74.3 & - & - & 82.5 & 71.6 \\
\hline
\end{tabular}

minimum and maximum noise and the simulated data are shown by thick lines. For reference, also the range of background noise is indicated in the graph. For this airplane, the noise level is simulated to a satisfactory level within the full frame.

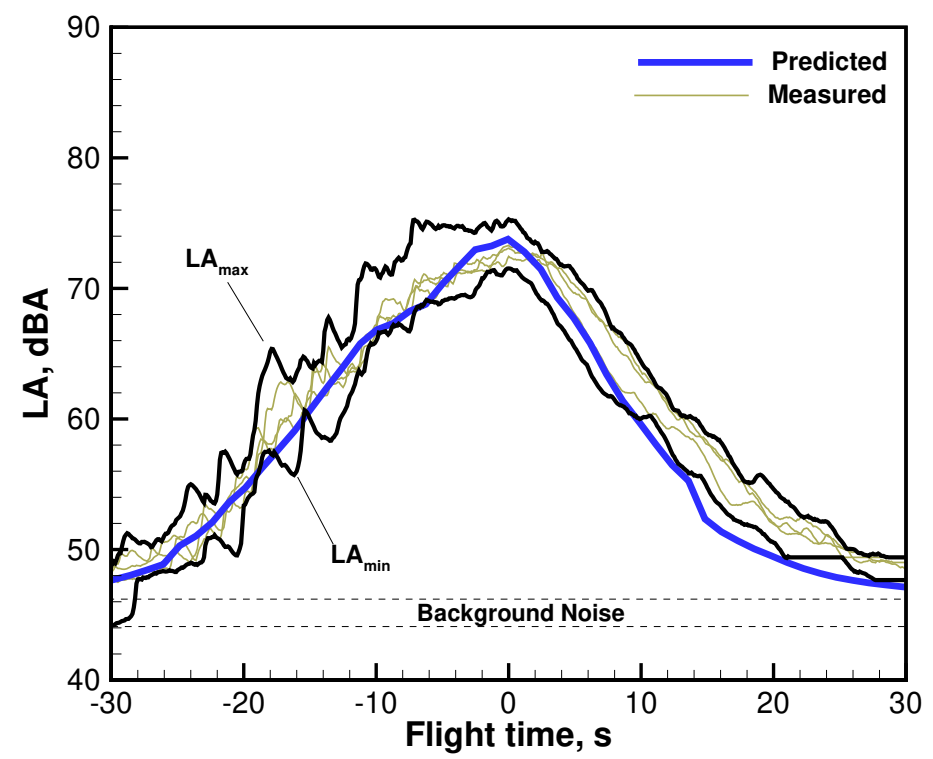

Figure 2: Noise measurements and predictions for the Airbus A319-111. Five flyovers available for this airplane.

The case of the Airbus A321-211 is not too dissimilar to the previous cases, with close prediction of the noise peak, but a general noise under-prediction on the upstream segment, Figure 4.

Next, we show the noise comparisons for the Airbus A330-243 and -343, both powered by RollsRoyce Trent 772 engines. According to the EASA noise certificate, the A330-243, with MTOW between 192 and 242 metric tons (weight configuration 026 and 081, respectively), has a flyover noise 


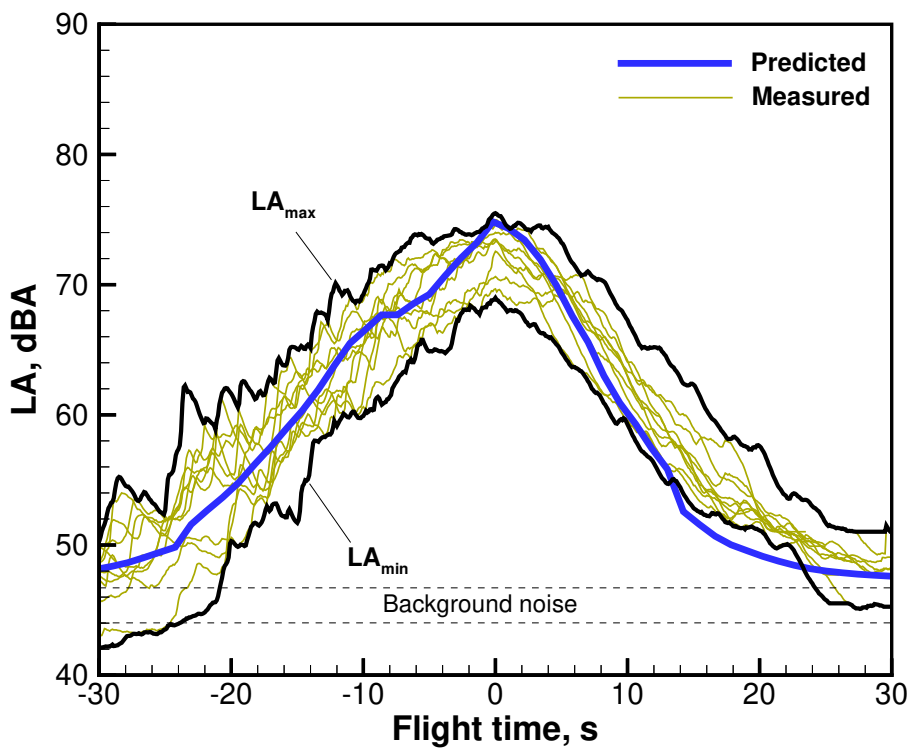

Figure 3: Noise measurements and predictions for the Airbus A320-214; eleven flyovers available.

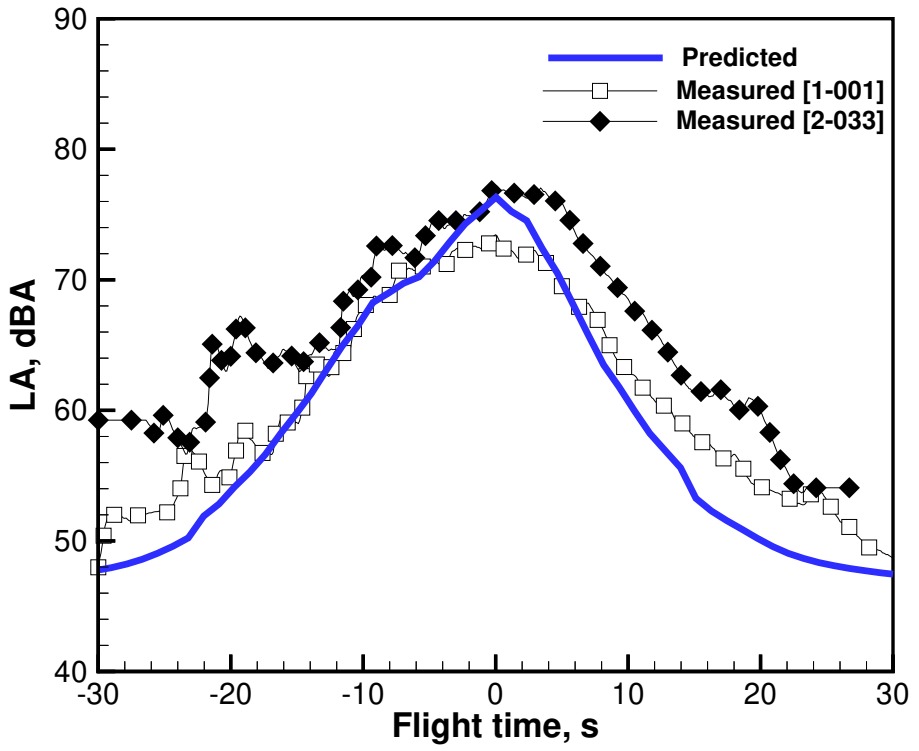

Figure 4: Noise measurements and predictions for the Airbus A321-211.

level between 85.4 and 91.9 EPNL(dB). The A330-343 has MTOW range between 190 and 233 metric tons (weight variants 032 and 052 , respectively). The certified flyover noise is substantially the same, between 85.5 and 91.9 EPNL (dB). We conclude that there should not be substantial differences between these airplanes at comparable take-off weights, unless different flight procedures are used.

In the measurements shown in Figure 5, a difference of $5 \mathrm{dBA}$ has been measured between the two aircraft versions. With a few flyovers, it is not possible to draw a robust conclusion. In absence of actual weight data, from an informal analysis of the airlines operating out of Manchester airport, 


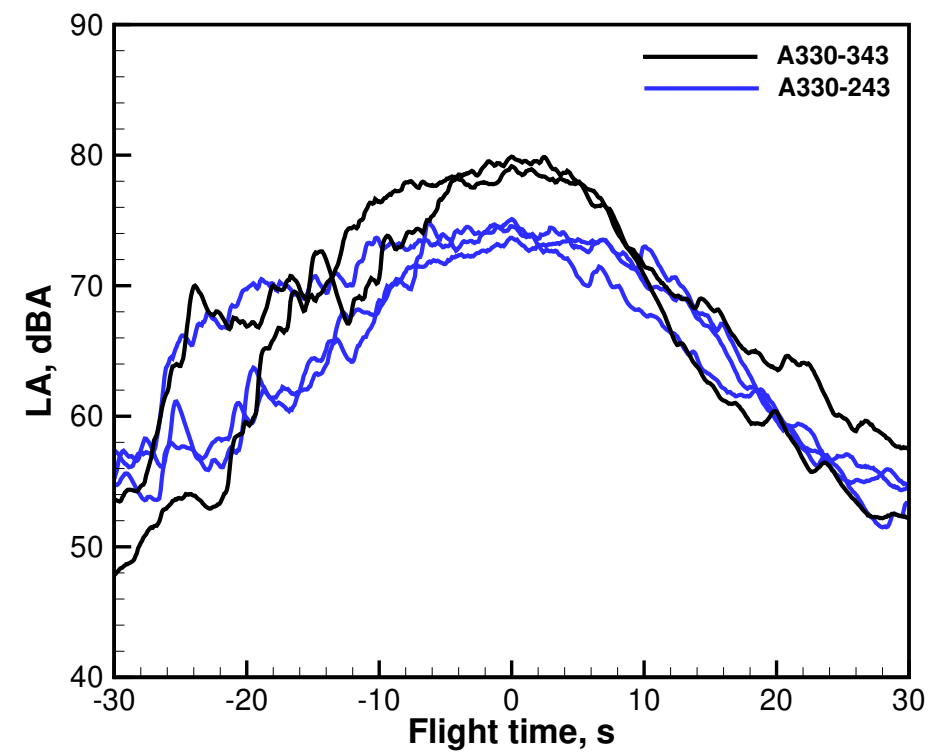

Figure 5: Noise measurements for the Airbus A330-243 and A330-343 airplanes.

we decided to assign a low gross weight to the A330-243, namely operating weight empty of 117 metric tons. The noise comparison is shown in Figure 6a. An excessive noise peak is predicted. This is due to excessive fan noise on the approach segment, and excessive jet noise on the departure side. By contrast, the noise peak is well predicted for the A330-343, Figure 6b.

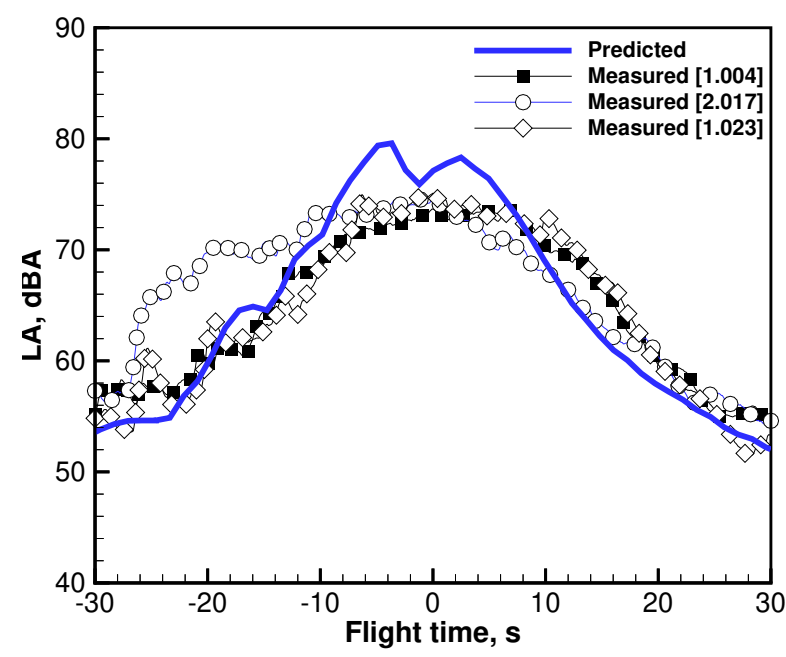

(a) A330-243

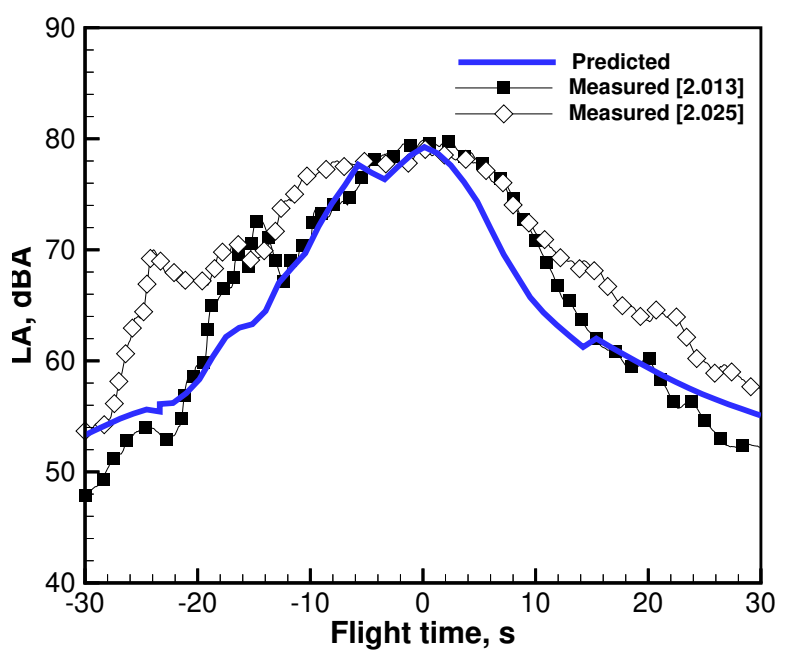

(b) A330-343

Figure 6: Noise measurements and predictions for the Airbus A330-243 with Trent 772 engines.

There are broadly similar conclusions for the case of the Airbus A350-900, as shown in Figure 7, in a comparison with three measured noise trajectories.

Noise comparisons for the Airbus A380-861 are less accurate, Figure 8. In support of this numerical result, it is noted that excess noise level is due to the fan on the upstream segment and to the 


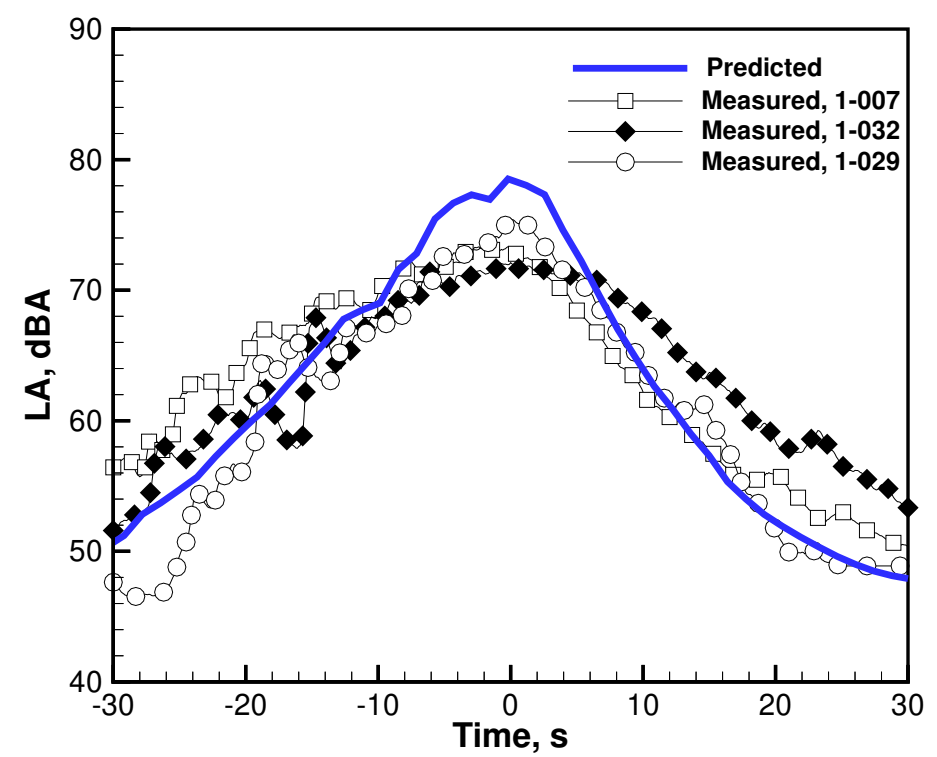

Figure 7: Noise measurements and predictions for the Airbus A350-900.

jet on the downstream segment. In the former case, the largest contribution is due to the inlet side; in the latter case, it is due to the transitional/intermediate-scale mixing noise, as shown in Ref. ${ }^{22}$.

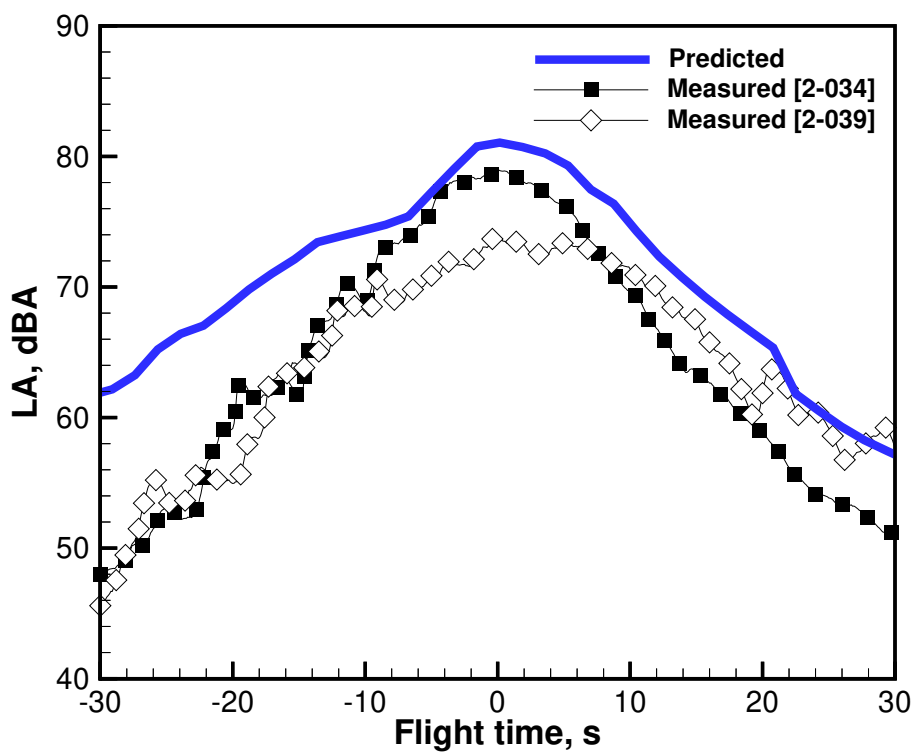

Figure 8: Noise measurements and predictions for the Airbus A380-861.

Field data indicate that there is $\Delta L_{\text {Amax }} \sim 5 \mathrm{dBA}$ (Table 1); this points to large variability in the noise level. However, we are able to conclude that in light of the fact that better comparisons were achieved with other airplanes, the discrepancy must be attributed to the airplane model and/or its flight trajectory, along with the acoustic models themselves.

Next, we consider Boeing airplanes. The first case is the Boeing B737-800; this is an airplane of 
widespread use and operating at most commercial airports around the world. Enough trajectories were available to draw a simple statistic analysis; however, only the actual noise recordings are shown in the graph. A comparison between field data and numerical simulations is shown in Figure 9. In a few instances, the noise measurement terminated before exiting the time frame, as the $L_{A m a x}$ in Figure 9. The predicted noise level is mostly within the confidence window, except for a period of 10-15 s on the downstream segment, where there is a noise under-prediction.

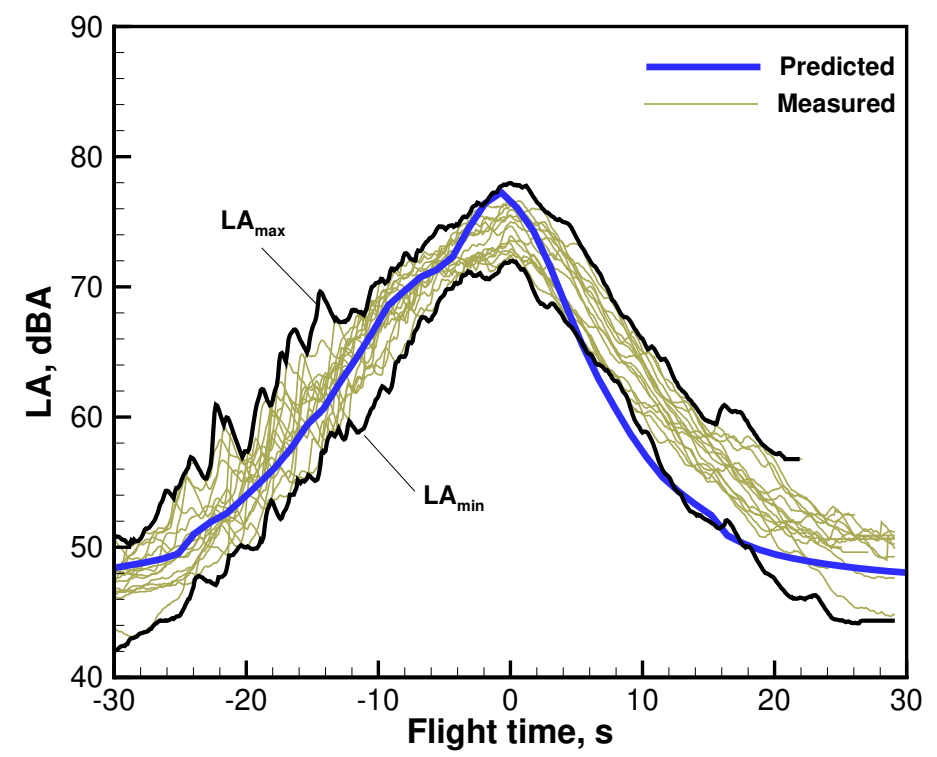

Figure 9: Noise measurements and predictions for the Boeing B737-800. Nineteen flyovers available for this airplane.

For the B757-200 only three trajectories were available, one of which unlikely to be correct, trajectory [1-006]; this event shown in Figure 10, with predictions matching exactly one of the trajectories on the downstream segment. However, differences of 8-10 dBA are noted on field data on the downstream segment.

Two versions of the Boeing B787 were available from the field noise data: the -800 and the -900 versions. The measured data are shown in Figure 11, and coloured by airplane version and measurement date. The two airplane versions in these measurements have the same engine type. The most important difference between the two airplane versions is that the -900 has a lower noise peak and a shallower noise reduction from the overhead position; the -800 version indicates that there is a sharper noise abatement from the noise peak position. It is not possible to make much inference on these differences without a detailed trajectory analysis, although noise peak differences of $5 \mathrm{dBA}$ are quite common (Table 1). However, for completeness, these two airplane versions were also simulated with the FLIGHT code. The comparison between simulation and measurements for the B-787-900 is shown in Figure 12a. The main discrepancy is in the noise peak, estimated at $\sim 4$ 


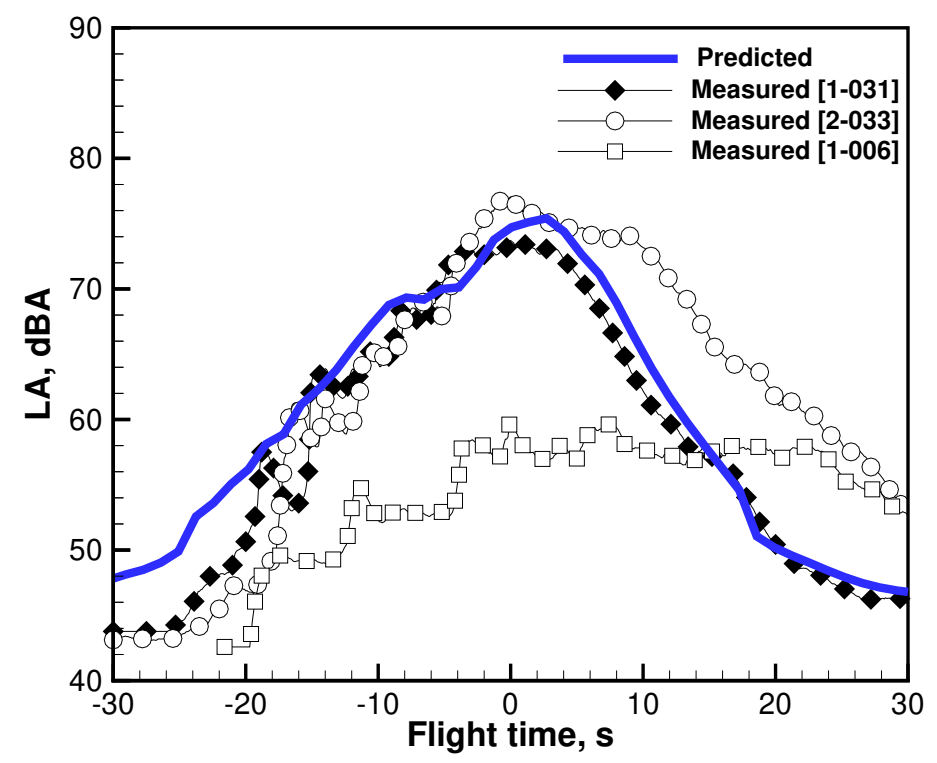

Figure 10: Noise measurements and predictions for the Boeing B757-200.

dBA. For the -800 version, the peak noise is well predicted, but the noise decay after the peak is over-estimated, Figure 12b. This is certainly not due to lateral dispersion of the flight track, since such an event is associated to a more shallow noise signal (lower peak, longer noise decay).

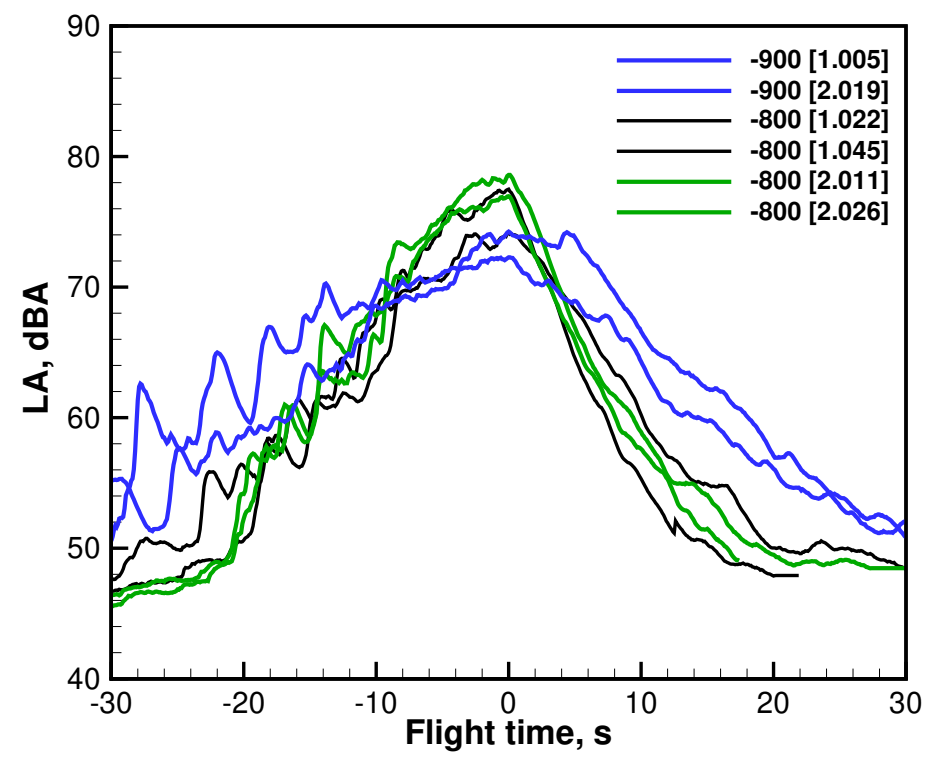

Figure 11: Field noise measurements for the Boeing B787-800 and -900.

An analysis of the sub-components reveals that this excess noise is due to the jet. Jet noise is modelled with an implementation of the Stone model ${ }^{22}$, with geometric parameters as part of the airplane configuration and the aero-thermodynamic parameters at the nozzle from the engine model. The engine model is the same for the two airplane versions. Since the previous case of the B787-900 
did not show such an under-prediction, it must be assumed that the thrust cut back on this phase of the climb-out is rather different from the simulated thrust schedule. From a report of departures at London Heathrow airport ${ }^{23}$, it has been established that airlines optimise their flight profiles, with essentially similar climb profile of up to 1,500 feet; above this altitude, the trajectories have altitude differences up to 900 feet at $8.5 \mathrm{~km}$ (4.6 n-miles) from brake-release. Thrust settings are variable not necessarily to reduce noise, but also to reduce engine wear costs.

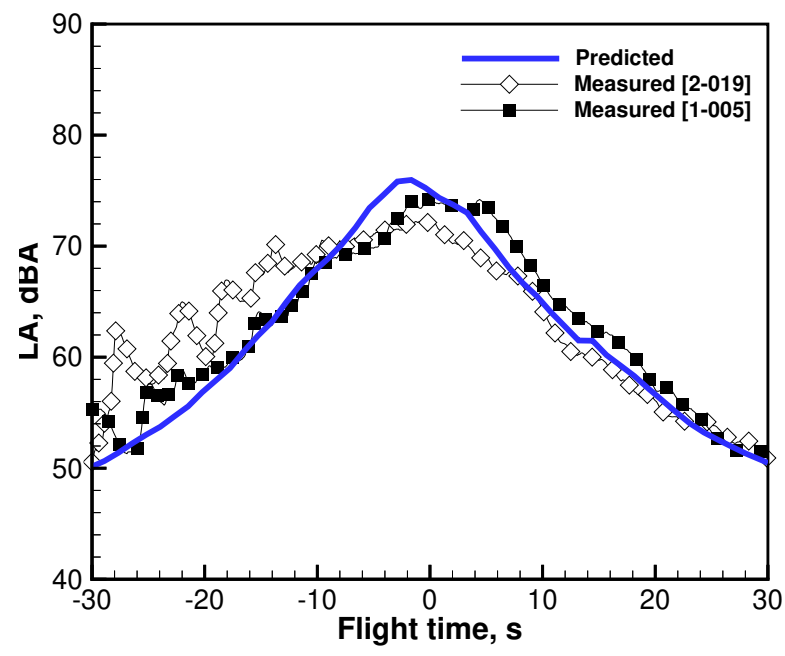

(a) B787-900

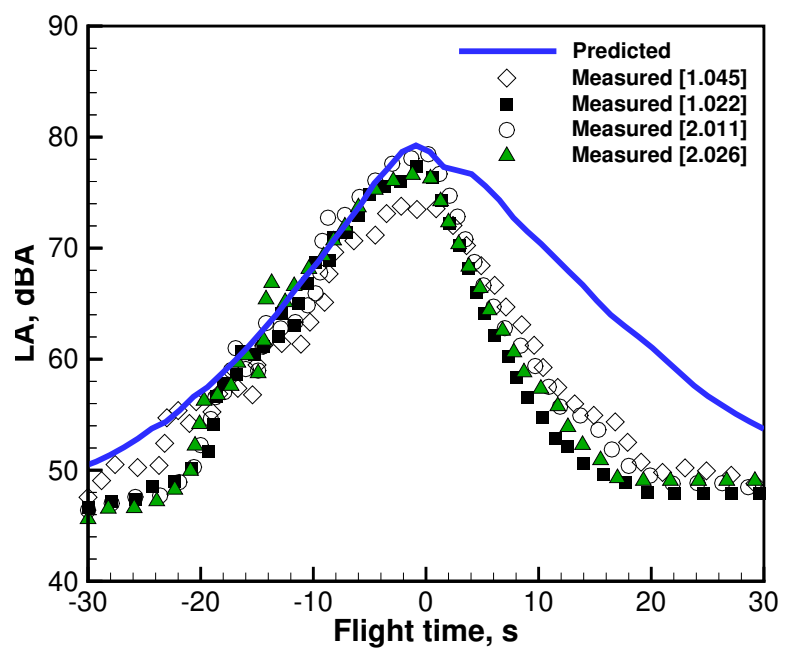

(b) B787-800

Figure 12: Noise measurements and predictions for the Airbus B787-900 and -800.

Flight trajectories elaborated from Ref. ${ }^{23}$ for the B787 are shown in Figure 13 to demonstrate the vertical spread. The data, which are only classified by airline and do not include take-off weight specification, refer to a mix of Rolls-Royce Trent and General Electric GEnx engines, with the lowest and highest trajectories corresponding to Trent engines. For reference, a simulated B787-800 trajectory with $95 \%$ engine derating is also shown, to demonstrate that the default trajectory is well within the envelope of the flight data. In our model, at 3,000 feet AGL the flight is forced to a level acceleration. Ground track dispersion on departure cannot be neglected; therefore, blind simulations like the present ones are limited by the amount of knowledge available on the specific flight.

The final case of turbofan airplane is the Embraer ERJ-195, for which only one field measurement was available. Figure 14 shows the comparison between numerical simulations and both the slowmode $L_{A}$ and the fast-mode noise level $L_{A}$ (logged using a logging period of $100 \mathrm{~ms}$ to provide a higher resolution). The noise shown in Figure 14 is about 3 dBA lower for the ERJ-175 airplane. 


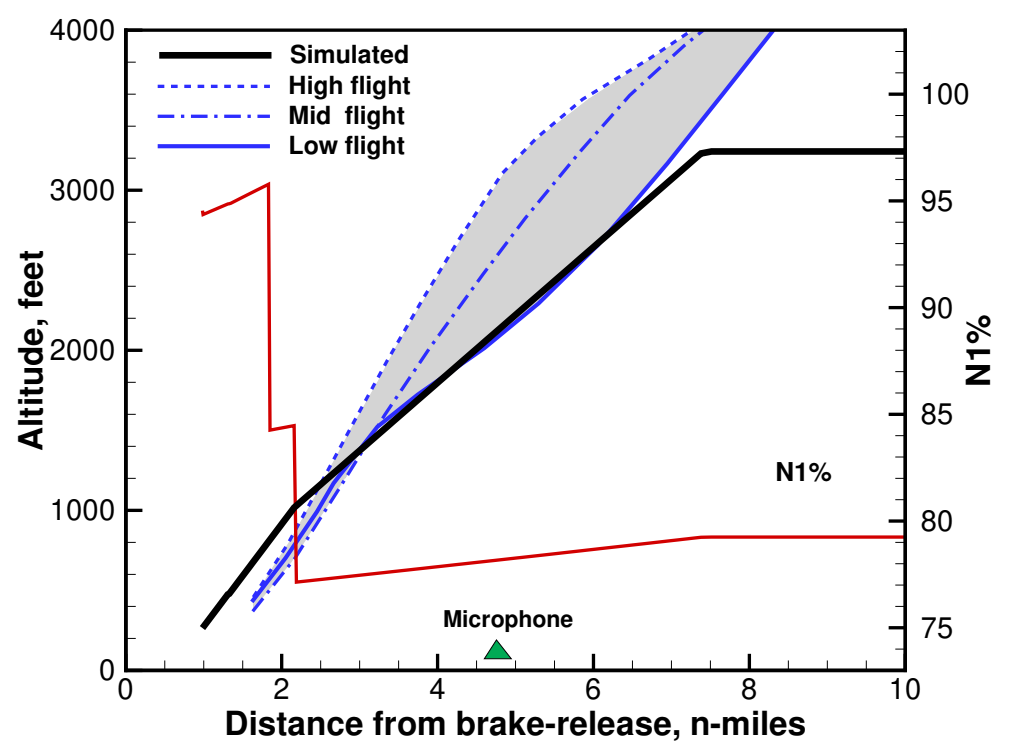

Figure 13: Vertical profile of B787 departure trajectories at London Heathrow ${ }^{23}$.

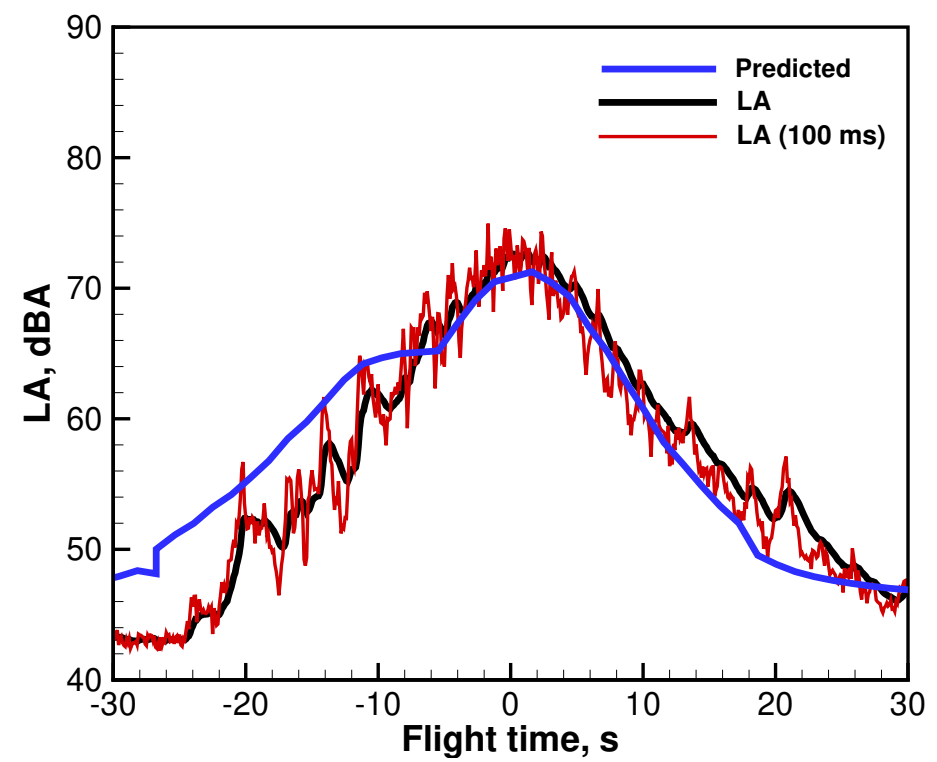

Figure 14: Noise measurements and predictions for the Embraer ERJ-195.

\section{Trajectory Optimisation for Minimum Emissions}

A detailed description of the numerical method used for trajectory optimisation is available in ${ }^{19}$. In brief, the optimal trajectory problem is described an optimal control problem with three control variables $\boldsymbol{u}=\left[N_{1}, \gamma, \phi\right]^{T}$ which are the inputs of the dynamics system formed by the state variables $\boldsymbol{x}=[V, \gamma, \chi, x, y, z, m]^{T}$. Briefly, the departure trajectory is optimised subject to the cost functions

$$
\min J_{1}=\mathrm{EPNL}, \quad J_{2}=\mathrm{CO}_{2}
$$


Since the cost function cannot be explicitly expressed by the derivatives of the dynamics variables, a multi-objective evolutionary algorithm, namely the Non-dominated Sorting Genetic Algorithm II ${ }^{24}$, is adopted for its performance and fast convergence.

To discretise the problem, the trajectory is segmented in the vertical plane and parametrised with Bézier splines in the horizontal plane. The number of free parameters required for this multi-objective optimisation problem is reduced to eight:

$$
\mathbf{P}=\left[\gamma_{A}, V_{B}, z_{B}, \gamma_{B}, V_{D}, N_{1 C D}, x_{c}, y_{c}\right]^{T}
$$

The underscores $A, B, C, D$ refer to the control points in the climb-out trajectory shown in Figure 15.

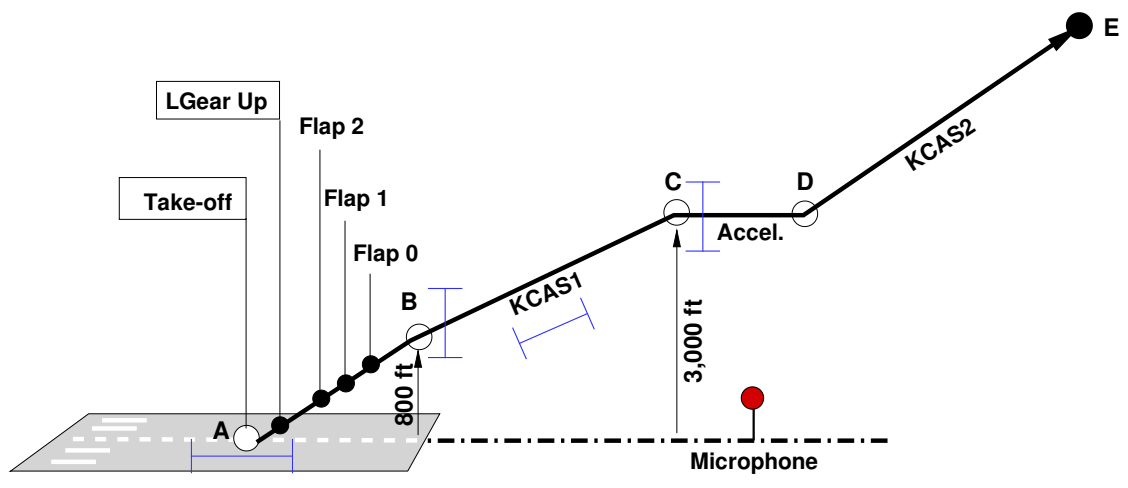

Figure 15: En-route aircraft climb with control points $A, B, C, D, E$.

Two posterior selection strategies are adopted to evaluate Pareto optimal solutions obtained by the optimiser by transferring and valuing environmental indexes of different physical characteristics with a single metric. The first one is the aggregated preference value function method based on the physical programming theory to classify and quantify the criteria by introducing decision makers' (DM) professional knowledge and experience ${ }^{25 ; 26}$.

After each objectives is assigned a preference value $n_{i}(x)$, the decision-making process is to find the solution with the minimum $V(x)$ :

$$
\min _{x} V(x)=\sum_{i=1}^{M} n_{i}(x)
$$

where $M$ is the total number of objectives. The latter one is the monetisation method which focuses more on the cost effectiveness of the objectives (fuel burn, noise level and engine exhaust emissions) of the solutions obtained, which depends more on the environmental policies and their damage costs. The unit cost of noise protection for a population ${ }^{27}, U$, is widely-used for environmental noise problems. The noise-induced damage cost can be expressed as: 


$$
\text { Cost of awakening }=\sum U_{k} P_{a, k} \mathcal{P}_{k}
$$

where $P_{\mathrm{a}, \mathrm{k}}$ is the probability of awakening of people living in the $k^{\text {th }}$ noise sensitive zone enclosing a population of size $\mathcal{P}_{k}$. The Sound Exposure Level (SEL) at Knutsford is used to calculate the cost of awakening in the process of posterior selection. The method proposed by the ANSI (American National Standards Insititute) is adopted to predict the probability of an individual noise event awakening a person as a result of the $\mathrm{SEL}^{28}$

$$
P_{\mathrm{a}, \mathrm{k}}=\frac{1}{1+e^{-\left(-6.8884+0.04444 \mathrm{SEL}_{\text {indoor }}\right)}}
$$

where $\mathrm{SEL}_{\text {indoor }}=\mathrm{SEL}_{\text {outdoor }}-20.5 \mathrm{~dB}$. $U$ is assigned the average total costs per person affected by noise prior to the implementation of noise reduction measures, which is discussed in Ref. ${ }^{29}$.

For the carbon emissions, the social cost of carbon $^{30}$ is used; this term reflects the economic cost of climate change caused by one additional metric of carbon dioxide emitted. As for the cost of other pollutants such as $\mathrm{NO}_{x}$, the cost of damage for average transport ${ }^{31}$ is used for aircraft flight operations. The posterior selection is to choose the minimum economic cost $C_{\min }$ of the optimised solutions:

$$
C_{\text {min }}=U \mathcal{P}+\mathrm{UDC}_{\mathrm{NO}_{\mathrm{x}}} \cdot \mathrm{NO}_{\mathrm{x}}+\mathrm{UDC}_{\mathrm{CO}_{2}} \cdot \mathrm{CO}_{2}+\mathrm{UC}_{\text {fuel }} \cdot m_{\text {fuel }}
$$

where UDC is the unit damage cost and $m_{f u e l}$ is the fuel burn.

\subsection{Optimal Departure Trajectories}

We considered three aircraft in different weight classes to evaluate the environmental emissions on departure. These aircraft: Embraer ERJ-195, Airbus A320-211 and Airbus A380-861. Since there is a residential community near the end of runway 23R/05L in Knutsford, a UK gridded population based on the 2011 Census and the 2007 Land Cover Map ${ }^{32}$ is introduced to estimate the exposure impact by the aviation activities. The gridded population data based on the British National Grid (OSGB36 datum) has a $1 \mathrm{~km}$ by $1 \mathrm{~km}$ spatial resolution for each square cell. To simplify the problem, it is assumed that all the population enclosed in the grid is gathered in the geometric centre of it, so the noise impact on that grid cell will be estimated using the noise level (expressed in terms of EPNL) received at that single point. A noise-sensitive region of $3 \mathrm{~km} \times 3 \mathrm{~km}$ in the town of Knutsford (coordinates: $53.30329^{\circ} \mathrm{N}, 2.37316^{\circ} \mathrm{W}$ ) with a population grid cell size of $1 \mathrm{~km}$ by $1 \mathrm{~km}$ is used for the analysis on the departure operation.

Note that $J_{1}$ is the EPNL measured at the centre of the cell at Knutsford. With the origin coordinate located at the end of runway $23 \mathrm{R} / 05 \mathrm{~L}$, the aircraft has initial condition $x_{0}=-916.7$ $\mathrm{m}, y_{0}=-399.6 \mathrm{~m}, z_{0}=73 \mathrm{~m}, V_{0}=75 \mathrm{~m} / \mathrm{s}$. The final point $\left\{x_{f}, y_{f}\right\}=\{-18,119,-16,709\}$ 
$\mathrm{m}$, is defined with the reference of an existing instrumental departure routing known as SANBA 1R1Y Noise Preferential Routing. Based on the method proposed in $\operatorname{Ref}^{19}$, the lateral track to be optimised is segmented into the initial straight leg and the following Bézier curve segment with one free control point $\left(x_{c}, y_{c}\right)$. The 3D trajectory is fully described by 8 free parameters, and the original optimal control problem is discretised into a parameter optimisation problem. Table 2 shows the free parameters settings. In this table, $\gamma$ is the flight path angle, $V$ is the airspeed, $z$ the flight altitude.

Table 2: Free parameters settings

\begin{tabular}{crr}
\hline Parameter & Lower bound & Upper bound \\
\hline$\gamma_{A}$ & 3 degrees & 12 degrees \\
$V_{B}$ & $80 \mathrm{~m} / \mathrm{s}$ & $100 \mathrm{~m} / \mathrm{s}$ \\
$z_{B}$ & $243.8 \mathrm{~m}$ & $457.2 \mathrm{~m}$ \\
$\gamma_{B}$ & 3 degrees & 12 degrees \\
$V_{D}$ & $80 \mathrm{~m} / \mathrm{s}$ & $125 \mathrm{~m} / \mathrm{s}$ \\
$N_{1}$ & $70 \%$ & $103 \%$ \\
$x_{c}$ & $-16,000 \mathrm{~m}$ & $-6,000 \mathrm{~m}$ \\
$y_{c}$ & $-4,000 \mathrm{~m}$ & $8,000 \mathrm{~m}$ \\
\hline
\end{tabular}

Figure 16 shows the tracks following the SANBA $1 Y$ routes for the three optimal trajectories subject to minimum EPNL at Knutsford (South of the plotted map) and minimum environmental cost. Note the lateral spreading in excess of 2,000 m from the E195 to the A320. The latter airplane is able to make a rapid manoeuvre away from the built-up area, North of the lake, before turning South. The ground track differences between noise-alone and total environmental cost are minimal.

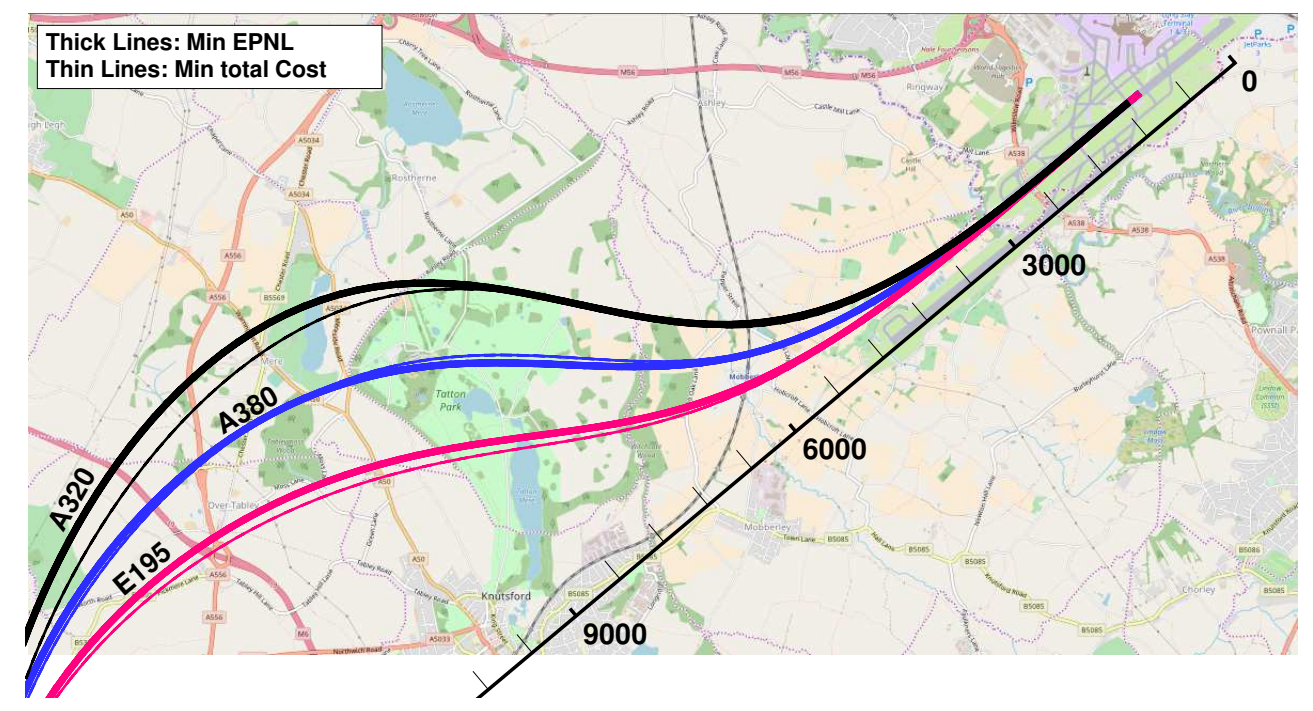

Figure 16: Optimal trajectories, subject to minimum EPNL (thick lines) at Knutsford and subject to minimum environmental cost (thin lines). Map elaborated from the website OpenStreetMap.

A similar scenario, using the fuel (or $\mathrm{CO}_{2}$ ) emissions as a cost function, shows less lateral spread- 
ing, Figure 17, and a less curved trajectory to reach the target altitude, with the airplanes passing above the lake. The E195 and the A320 airplanes would be roughly above the noise measuring station discussed earlier. The vertical flight profiles are shown in Figure 18, which again shows a large variability in terms of altitudes and speeds. For the same airplane (for example, the Airbus A380), a comparison of Figures 18a and 18c indicates that the vertical variability for minimum noise and minimum fuel is considerably smaller. There is only minimal difference between the minimum-EPNL and minimum-cost vertical profiles, Figure 18a and 18b.

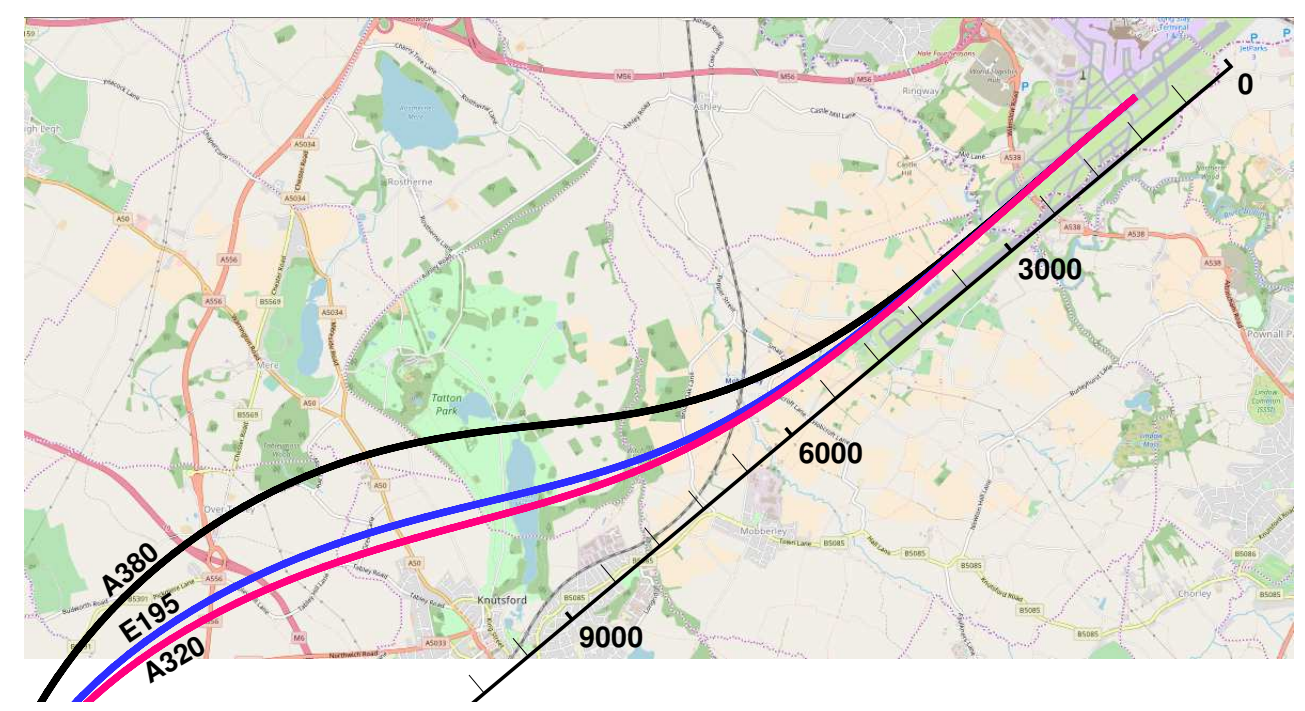

Figure 17: Optimal trajectories, subject to minimum fuel burn and minimum $\mathrm{CO}_{2}$ (minimum fuel to a target altitude). Map elaborated from the website OpenStreetMap. 


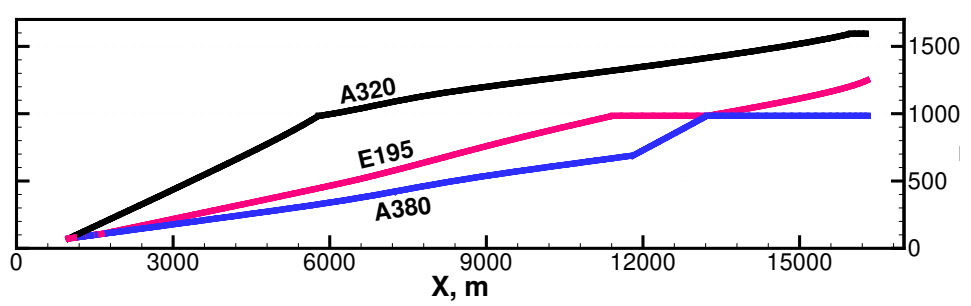

(a) minimum EPNL

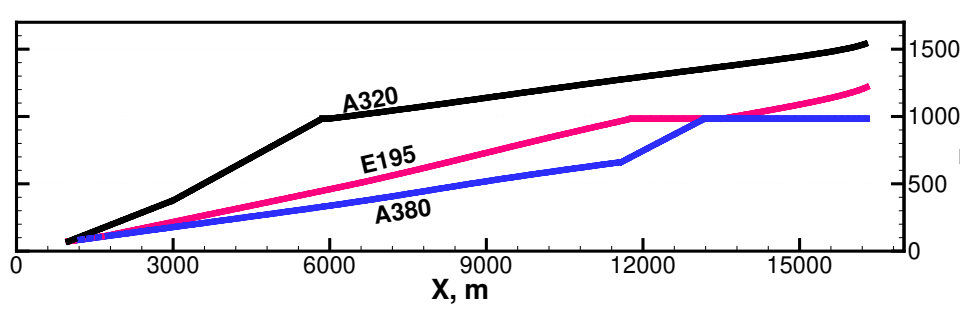

(b) minimum $\mathrm{CO}_{2}$

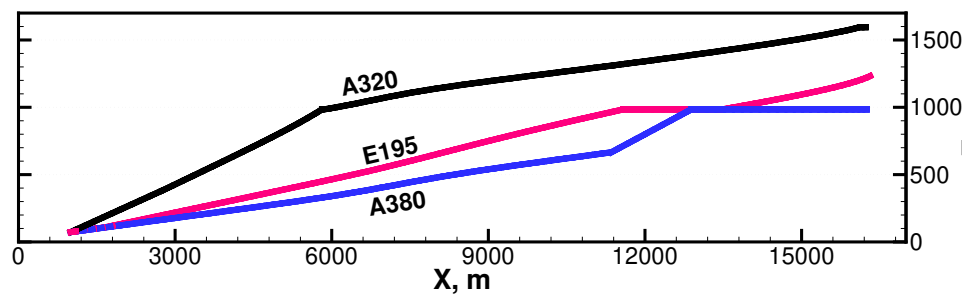

(c) minimum total cost

Figure 18: Optimal climb profiles of three airplane models; these are the same flights as in Figures 1617. There are only minor differences between cases a.) and b.)

\subsection{Sensitivity Analysis}

The sensitivity of the aircraft systems parameters (by themselves uncertain) has been carried out for the minimum-noise trajectory of the Airbus A320-211. By using this trajectory, whose track is shown in Figure 16, we have inserted random perturbations on 19 uncorrelated key aircraft and operational parameters ( 7 engine parameters, 5 airframe parameters, 3 atmospheric parameters, 3 aircraft position data and ground impedance values). Previous work showed a sensitivity analysis for single-parameter perturbations ${ }^{14}$. In this instance, we define a perturbation vector $d \mathcal{V}$

$$
d \mathcal{V}=\left\{V_{i}\left(1 \pm \mathrm{RND} r_{i}\right)\right\}
$$

where $r_{i}$ is the amplitude of the parameter $V_{i}$ and RND is a random number; thus, a generic parameter $V_{i}$ can vary uniformly at random within the range $\left[V_{i}-r_{i}, V_{i}+r_{i}\right]$. Engine parameters such as mass flow rate, fuel flow, exhaust gas temperature, engine speed, etc. have an amplitude of $1.5 \%$ to $3 \%$ 
around the reference values. Airframe parameters (nozzle geometry, inlet duct, etc.) are varied by $10 \%$ and aircraft position is varied as much as a fuselage length in all directions.

A run with 30 random vectors, Eq. 8, has led to a perturbation result shown in Figure 19. We note that there can be a $\pm 2 \mathrm{EPNL}(\mathrm{dB})$ and $\pm 2 \mathrm{~dB}$ in $L A_{\max }$ uncertainty in the result compared to the baseline case. The standard deviation is estimated as $0.9 \mathrm{EPNL}(\mathrm{dB})$ and $0.45 \mathrm{~dB}$, respectively. These sensitivities are not dissimilar to the uncertainties verified in the noise measurements.

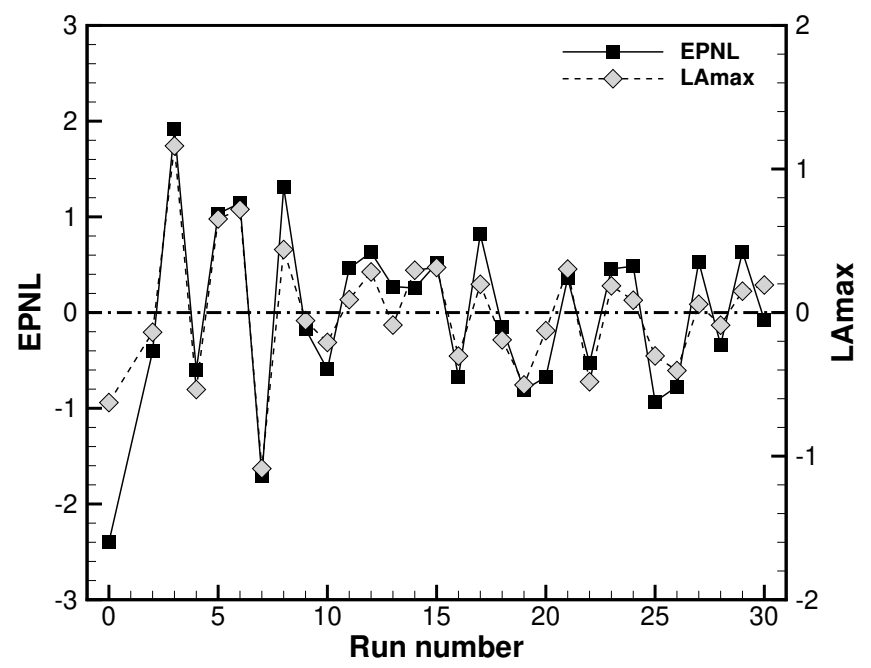

Figure 19: Noise sensitivity analysis for an optimal departure trajectory of the Airbus A320-211.

\section{Conclusions}

Comparisons of noise emissions are shown for 12 different commercial airplanes during normal operations at a major international airport. Simulations have been carried out with a multi-disciplinary environmental computer code that contains a mix of models, some based on physics and others based on empirical evidence. Noise measurements were taken at a single point on the departure side to provide validation data. It was not possible to gather data at multiple locations.

It is demonstrated that flyover noise from commercial airplanes can be predicted to a good level of accuracy over a flight time of the order of 40 to 60 seconds, centred around the overhead position. This conclusion holds also in consideration of large uncertainties surrounding the flight parameters and in relatively poor atmospheric conditions.

A subset of airplane models in the FLIGHT program has been validated for flyover noise predictions. There remain a number of cases for which the comparisons between numerical simulations and field data show a discrepancy that cannot be explained with the data at hand (Boeing B787-800 and A380-861).

The field measurements themselves show a degree of variability, above $\sim 5 \mathrm{dBA}$, the overhead 
position, and up to $15 \mathrm{dBA}$ at flight times $t \sim \pm 20 \mathrm{~s}$ around the overhead position. Although the specific reasons could not be investigated, because we had no access to airplane data, it is reasonable to assume that the flight path and the thrust settings are the dominant causes. These effects have been further investigated by adding a sophisticated multi-objective multi-parameter flight trajectory optimisation algorithm. The new optimisation module was applied to three airplane models, among those verified in the noise comparisons.

Further to these effects, local atmospheric effects are known to be responsible for large changes in sound pressure level at large distances. Minimum airplane distances in the cases analysed were always of the order of several hundred metres, which makes random effects more plausible. Overall, the comparisons between field data and the numerical simulations are better for those cases where a larger set of trajectories was available. This is entirely reasonable, since the statistics eliminates spurious data and reduces the uncertainty of the noise event.

Although the numerical results show margins for improvements, these have to be pursued only in parallel with dedicated field measurements, which must include details on the flight trajectory and the engine state. One of the main challenges in predicting aircraft noise is understanding which factors are important and which are inessential. This understanding greatly facilitates the task, and allows to focus the efforts only on those items that are likely to make an important difference.

By using several cost functions, either based on noise alone, or emissions alone, or combinations between noise and exhaust emissions, it is possible to optimise departure trajectories. The robustness of the method is demonstrated with three airplanes in three different weight classes and a sensitivity analysis has been included to assess the effects of system parameters on the resulting noise metrics.

An important advantage of the computer code is that it is not airport-dependent. Therefore, the study of optimal departure trajectories can be extended to any airport with any specific constraints, such as fixed way-points including obstacle avoidance (tall buildings or narrow valleys).

\section{Acknowledgments}

The author wishes to thank the student Yun Lee Wong for taking the field measurements. Adrian Harwood provided technical support with the measurements and the post-processing of the data. The park authorities at Tatton Park, Cheshire, UK, are thanked for allowing the measurements to take place over a two-day period in December 2017. Co-author Mengying Zhang wishes to acknowledge the financial support from China Scholarship Council (File No. 201403170405).

\section{References}

[1] Boeker ER, Dinges E, He B, Fleming G, Roof CJ, Gerbi PJ, Rapoza AS, and Hemann J. Integrated noise model (INM) Version 7.0. Technical Report FAA-AEE-08-01, Federal Aviation 
Administration, Jan. 2008.

[2] Ollerhead JB, Rhodes DP, Viinikainen MS, Monkman DJ, and Woodley AC. The UK civil aircraft noise contour model ANCON: Improvements in Version 2. Technical Report R\&D 9842, ERCD Dept., Civil Aviation Authority (CAA), Jun. 1999.

[3] ECAC. Report on standard method of computing noise contours around civil airports. Vol. 2: Technical guide. Technical Report Doc. 29, European Civil Aviation Conference, Dec. 2005.

[4] ICAO. Recommended Method for Computing Noise Contours Around Airports. Montreal, 2008. Doc. 9911.

[5] Lopes LV and Burley CL. Design of the next generation aircraft noise prediction program: ANOPP2. In 17th AIAA/CEAS Aeroacoustics Conf., AIAA 2011-2854, Portland, Jun. 2011.

[6] Crichton D, de la Rosa Blanco E, Law T, and Hileman J. Design and operation for ultra low noise take-off. In 45th AIAA Aerospace Sciences Meeting, AIAA 2007-0456, Reno, NV, Jan. 2007.

[7] Bertsch L, Dobrzynski W, and Guerin S. Tool development for low-noise aircraft design. J. Aircraft, 47(2):694-699, Mar. 2010.

[8] Filippone A. Aircraft noise prediction. Progress in Aerospace Sciences, 68:27-63, July 2014. DOI:10.1016/j.paerosci.2014.02.001.

[9] Guerin S, Michel U, and Siller H. Airbus A319 database from dedicated flyover measurements to investigate noise abatement procedures. In 11th AIAA/CEAS Aeroacoustics Conf., AIAA 2005-2981. Monterey, CA, May 2005.

[10] Pott-Pollenske M, Dobrzynski W, Buchholz H, Guerin S, Sauressig G, and Finke U. Airframe noise characteristics from flyover measurements and predictions. In 12th AIAA/CEAS Aeroacoustics Conf., AIAA 2006-2567, Cambridge, May 2006.

[11] Siller $\mathrm{H}$ and Michel U. Buzz-saw noise spectra and directivity from flyover tests. In 12th AIAA/CEAS Aeroacoustics Conf., AIAA 2002-2562. Cambridge, MA, May 2002. DOI:10.2514/6.2006-2464.

[12] Simons DG, Snellen M, van Midden B, Arntzen M, and Bergmans DHT. Assessment of noise level variations of aircraft flyovers using acoustic arrays. Journal of Aircraft, 52(5):1625-1633, 2015. DOI:10.2514/1.C033020. 
[13] Baughcum SL, Tritz TG, Henderson SC, and Pickett DC. Scheduled civil aircraft emission inventories for 1992: Database development and analysis. Technical Report NASA CR-4700, NASA, April 1996. Appendix D.

[14] Filippone A. Multi-disciplinary simulation of propeller-turboprop aircraft flight. Aeronautical J., 116(1184):985-1014, Oct 2012.

[15] Antonio Filippone and Nicholas Bojdo. Statistical model for gas turbine engines exhaust emissions. Transportation Research Part D: Transport and Environment, 59:451-463, 2018. DOI:10.1016/j.trd.2018.01.019.

[16] Filippone A. Advanced Aircraft Flight Performance. Cambridge Univ. Press, 2012.

[17] Filippone A. Theoretical framework for the simulation of transport aircraft flight. J. Aircraft, 47(5):1669-1696, Sept 2010. doi: 10.2514/1.C000252.

[18] Filippone A and Harwood A. Flyover noise measurements and predictions of commercial airplanes. J. Aircraft, 53(2):396-405, 2015. DOI:10.2514/1.C033370.

[19] Zhang M, Filippone A, and Bojdo N. Multi-objective optimisation of aircraft departure trajectories. Aerospace Science \& Technology, 2018. DOI:10.1016/j.ast.2018.05.032.

[20] Rasmussen KB. Sound propagation over grass covered ground. J. Sound E Vibration, 78(2):247255, 1981. DOI:10.1016/S0022-460X(81)80036-3.

[21] Almgren M. Simulation by using a curved ground scale model of outdoor sound propagation under the influence of a constant sound speed gradient. J. Sound $\&$ Vibration, 118(2):353-370, Oct. 1987. DOI:10.1016/0022-460X(87)90531-1.

[22] Stone JR, Krejsa EA, Clark BJ, and Berton JJ. Jet noise modeling for suppressed and unsuppressed aircraft in simulated flight. Technical Report TM-2009-215524, NASA, Mar. 2009.

[23] Anon. Noise data for the first 17 months of Boeing 787 operations at Heathrow airport. Technical Report CAP 1191, Civil Aviation Authority, Environmental Research \& Consultancy, Gatwick airport, July 2014. (available online).

[24] Deb K, Pratap A, Agarwal S, and Meyarivan TAMT. A fast and elitist multiobjective genetic algorithm: NSGA-II. Evolutionary Computation, IEEE Transactions on, 6(2):182-197, 2002. DOI:10.1109/4235.996017.

[25] Messac A. Physical programming-effective optimization for computational design. AIAA Journal, 34(1):149-158, 1996. DOI:10.2514/3.13035. 
[26] Sanchis J, Martínez MA, and Blasco X. Integrated multiobjective optimization and a priori preferences using genetic algorithms. Information Sciences, 178(4):931-951, February 2008. DOI:10.1016/j.ins.2007.09.018.

[27] Zaporozhets O, Tokarev V, and Attenborough K. Aircraft Noise: Assessment, Prediction and Control. CRC Press, 2011.

[28] Quantities and Procedures for Description and Measurement of Environmental Sound Part 6: Methods for Estimation of Awakenings Associated with Outdoor Noise Events Heard in Homes. Standard ANSI S12.9-2008/part 6, International Organization for Standardization, New York, USA, January 2008.

[29] The Centre for Strategy \& Evaluation Services LLP. Evaluation of Directive 2002/49/EC Relating to the Assessment and Management of Environmental Noise Finial Report. Publications Office of the European Union, Brussels, August 2016.

[30] Department of Energy and Climate Change. Carbon Valuation in UK Policy Appraisal: A Revised Approach. Technical Report, Department of Energy and Climate Change, July 2009.

[31] DEFRA. Valuing impacts on air quality: Updates in valuing changes in emissions of Oxides of Nitrogen (NOx) and concentrations of Nitrogen Dioxide (NO2). Technical report, Department for Environment, Food and Rural Affairs, Sept 2015.

[32] Reis S, Liska T, Steinle S, Carnell E, Leaver D, Roberts E, Vieno M, Beck R, and Dragosits U. UK Gridded Population 2011 based on Census 2011 and Land Cover Map 2015, 2017. 